International Journal of Engineering, Science and Technology

Vol. 2, No. 2, 2010, pp. 155-164
INTERNATIONAL

JOURNAL OF

ENGINEERING,

SCIENCE AND

TECHNOLOGY

www.ijest-ng.com

(c) 2010 MultiCraft Limited. All rights reserved

\title{
Influencing parameters on performance of a mantle heat exchanger for a solar water heater - a simulation study
}

\author{
G. Naga Malleshwara Rao ${ }^{1 *}$, K. Hema Chandra Reddy ${ }^{2}$, M. Sreenivasa Reddy ${ }^{3}$ \\ ${ }^{1 *}$ Intell Engineering College, Ananthapur, INDIA, \\ ${ }^{2}$ Academics and Planning, JNTUA, Ananthapur,INDIA \\ ${ }^{3}$ JNTUCollege of Engineering, Ananthapur, INDIA \\ *Corresponding Author, Email: mallesh@teachers.org, Mobile: +91-9441222930
}

\begin{abstract}
:
Thermal performance of a solar water heater mainly depends on the thermal stratification. Thermal stratification in solar water tanks is essential for a better performance of energy storage systems where these tanks are integrated. In this research work, the performance of a solar water heater with a mantle heat exchanger is investigated experimentally. The heat exchanger is assessed for a range of operating conditions to quantify both the mantle side and the tank side heat transfer coefficients and the effect of thermal stratification in the tank. The experiments arte simulated and validated by using CFD tool ANSYS-CFX and a good agreement is obtained between experiments and simulations. The objective of this paper is to investigate the influence of location of hot fluid inlet, mass flow rate of mantle fluid and type of hot fluid on the performance of the mantle heat exchanger.
\end{abstract}

Keywords: Performance of mantle heat exchanger, mantle side heat transfer coefficient, tank side heat transfer coefficient, operating conditions, ANSYS-CFX, hot fluid inlet, mass flow rate, type of hot fluid

\section{Introduction}

There are many good methods and sources used to store warm thermal energy. These include solar heaters, solar ponds, geothermal storage methods, and many others. The advantage of warm thermal energy storage is that usually, the warm thermal energy storage is obtained from an abundant and ecologically friendly source, such as the sun. As a result, heat storage is usually very cost friendly and good for the environment.

The main aim of this paper to investigate the influence of certain operating parameters which can affect the performance of the mantle heat exchangers. Location of hot fluid inlet into the mantle heat exchanger, mass flow rate of mantle fluid, heat transfer fluid are the three parameters that influence the performance of a mantle heat exchanger. An effort is made through this work to study the effect of the above parameters on the performance of mantle heat exchanger. Further details on the parameters considered are discussed in section 3.

Figure 1 shows a solar domestic hot water system with a vertical mantle heat exchanger. The mantle fluid is slowly pumped down through the mantle in order to exchange heat between the mantle fluid and the water in the tank.

\section{Solar water heater with mantle heat exchanger}

A mantle tank is a cylindrical storage tank surrounded by an annulus through which hot liquid from the collector flows thereby transferring energy to the tank contents. The separating wall is the heat exchange surface. Wrap-around coil and tank-in-tank systems are similar in this respect. Wrap-around coil designs usually have a smaller fluid inventory than mantle tanks and operate with higher flow rates to produce turbulent conditions within the coil. Tank-in- tank systems allow the top and bottom of the water storage tank, in addition to the sides, to serve as heat exchanger surface. Mantle heat exchangers are an interesting alternative to external heat exchangers because they reduce the complexity of the system by combining the heat exchanger and the storage unit in one element. In a mantle heat exchange system, fluid flow from the heat source does not pass through the tank. A possible 
advantage of this flow configuration is reduced internal tank mixing and, as a consequence, improved temperature stratification resulting in higher solar collector efficiency (Furbo and Knudsen, 2005; Knudsen and Furbo, 2004).

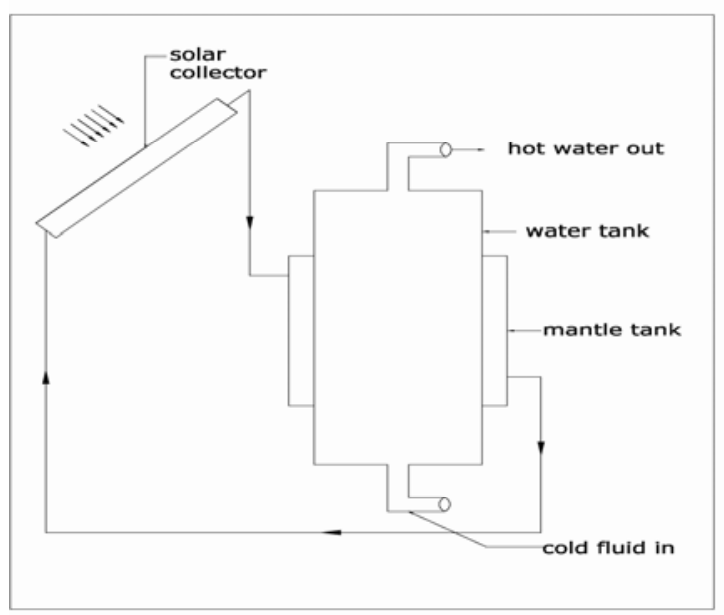

Figure 1: Solar water heater with mantle heat exchanger

\subsection{Salient Features of the Mantle Heat Exchanger System:}

A). Thermal Stratification: The mantle tank system is one of the simplest ways of producing high heat exchanger effectiveness while promoting thermal stratification. The mantle configuration provides a large heat transfer area and effective distribution of the collector loop flow over the wall of the tank. Most of the incoming mantle fluid seeks the thermal equilibrium level in the mantle, and thermal stratification in the mantle and the inner tank is not disturbed (Shah and Furbo, 1998).

B). Cost: The cost of tank is less compared to the increased performance initiated by the fine thermal stratification (Shah, 2000). C). Size limitation: The mantle tank design is not suitable for large low flow SDHW systems, as the heat transfer area gets too small for tanks with volumes over 800-1000 lts. (Shah et al., 1999).

\section{Experimental equipment, procedures and experimental parameters}

\subsection{Description of experimental equipment}

In this paper, the convective heat transfer at the mantle wall and at the tank wall is investigated under operation conditions. In this study, the convective heat transfer in the mantle and in the inner tank is analysed by means of dimensionless heat transfer theory in order to obtain heat flux and heat transfer coefficients for vertical mantle heat exchangers. It is not enough only to be able to predict the heat transfer at the mantle wall and at the tank wall to model the thermal stratification in the inner tank, it is also necessary to know the heat transfer at different levels due to the heat flows inside the inner tank.

An effort is also made to model heat transfer in energy storage tank with mantle heat exchanger. A schematic diagram of a solar domestic water heater with a mantle heat exchanger as shown in Figure 1.

An experimental arrangement of a vertical mantle heat exchanger for the solar water heater as illustrated in Figure 2 . The purpose of this experimentation is to evaluate the overall heat transfer characteristics of the mantle heat exchanger over a range of mantle flow rates and thermal boundary conditions. These experiments are carried out at heat transfer laboratory of JNTU College of Engineering, Ananthapur, Andhra Pradesh, India.

The mantle is constructed with an annular spacing of $30 \mathrm{~mm}$ wrapped around the bottom half of a stainless steel (SS 304 grade) tank. The tank is insulated with glass wool. In the experiments hot water is supplied to the hot side of the heat exchanger from a conventional hot water tank as the heat source and the cold water is supplied from the bottom side of the storage tank.

Eight thermocouples (copper-constantan) are fitted at different levels inside the core of the tank and four thermocouples (copperconstantan) are mounted on the mantle tank wall side of the heat exchange surface, to measure tank temperatures at different locations as shown in Figure 3 to know the stratification. The inlet and outlet temperatures and flow rate of the hot water (mantle fluid) through the heat exchanger are also measured. A $31 / 2$ digit digital display unit is used to display the temperatures. All the instruments used in these experiments are well calibrated with standard instruments. 


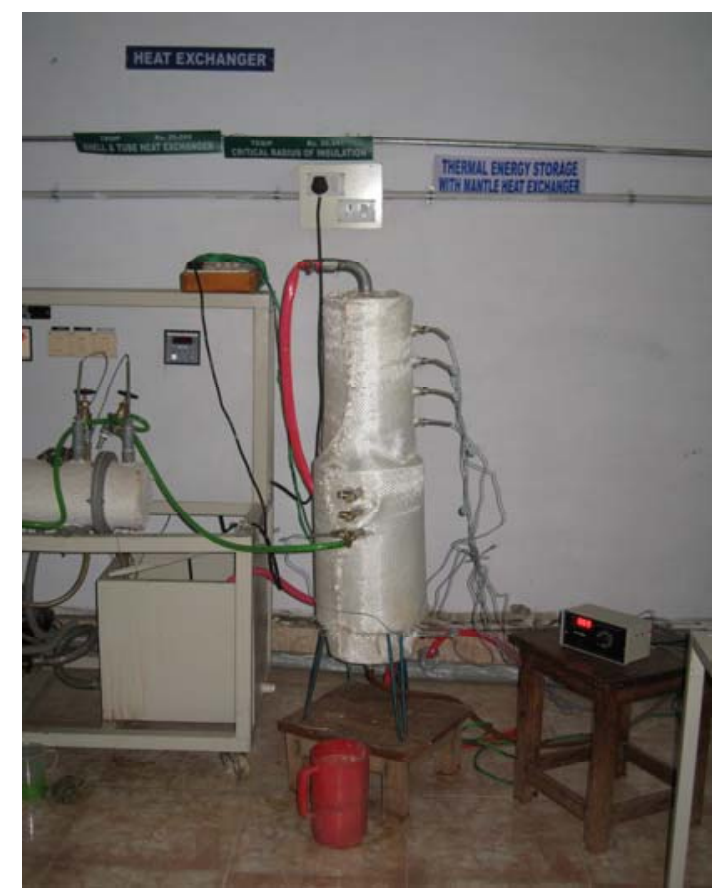

Figure 2: Photographic view of Experimental set-up.

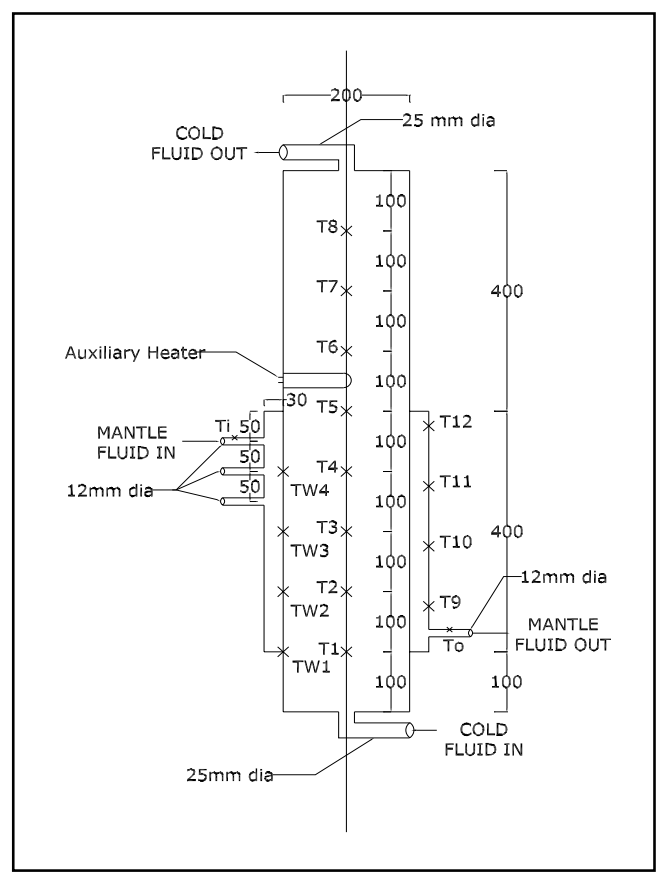

Figure 3: Temperature measuring points for Solar water tank with mantle heat exchanger.

The details of mantle type heat exchanger fabricated for the purpose of experimentation are given in Table 1.

Table 1. Details of Mantle heat exchanger

\begin{tabular}{|c|c|c|c|}
\hline \multicolumn{2}{|l|}{ Data Of Mantle Tank } & \multicolumn{2}{|c|}{ Stainless Steel Properties: Grade: SS304 } \\
\hline Volume in inner tank $\left[\mathrm{m}^{3}\right]$ & 0.5585 & Specific heat $[\mathrm{J} / \mathrm{Kg} . \mathrm{K}]$ & 460 \\
\hline Volume in inner tank above mantle $\left[\mathrm{m}^{3}\right]$ & 0.246 & Density $\left[\mathrm{Kg} / \mathrm{m}^{3}\right]$ & 7820 \\
\hline Tank height [m] & 0.900 & $\begin{array}{l}\text { Thermal } \\
\text { Conductivity }\left[\mathrm{W} / \mathrm{m}^{2} . \mathrm{K}\right]\end{array}$ & 15 \\
\hline Inner diameter of tank $[\mathrm{m}]$ & 0.1976 & \multirow{2}{*}{\multicolumn{2}{|c|}{ INSULATION: }} \\
\hline Thickness of tank wall [m] & 0.0012 & & \\
\hline Mantle height $[\mathrm{m}]$ & 0.400 & Material & Glass Wool \\
\hline Mantle tank diameter $[\mathrm{m}]$ & 0.260 & Insulation top, $[\mathrm{m}]$ & 0.006 \\
\hline Mantle top (distance from bottom of tank) [m] & 0.500 & $\begin{array}{l}\text { Insulation side above/below } \\
\text { mantle, }[\mathrm{m}]\end{array}$ & 0.006 \\
\hline Mantle bottom(distance from bottom of tank) [m] & 0.100 & \multirow{2}{*}{ Insulation side mantle, $[\mathrm{m}]$} & \multirow{2}{*}{0.006} \\
\hline Mantle gap width [m] & 0.030 & & \\
\hline Mantle inlet position from top of mantle[m] & $\begin{array}{l}0.05 / 0.10 / \\
0.15\end{array}$ & \multirow{3}{*}{ Insulation bottom, $[\mathrm{m}]$} & \multirow{3}{*}{0.006} \\
\hline Mantle inlet size [ inner diameter ] [m] & 0.012 & & \\
\hline Hot water tank volume $\left[\mathrm{m}^{3}\right]$ & 0.073 & & \\
\hline Inner tank inlet size $[\mathrm{m}]$ & 0.0254 & Mantle Fluid & Water \\
\hline
\end{tabular}

\subsection{Experimental procedures}

In this study, with a mantle inlet size of $12 \mathrm{~mm}$, tests with two different locations of the mantle inlet port are carried out, that is top inlet position and lower inlet position. The top (first) inlet is positioned $50 \mathrm{~mm}$ below from the top of mantle tank and that of lower (second) inlet is positioned at $100 \mathrm{~mm}$ below the top of the mantle tank (one fourth of the total mantle height). All the experiments are performed with two mass flow rates of mantle fluid at $0.5 \mathrm{lit} / \mathrm{min}(0.00833 \mathrm{~kg} / \mathrm{sec})$ and $0.75 \mathrm{lit} / \mathrm{min}(0.0125$ $\mathrm{kg} / \mathrm{sec}$ ). Two heat transfer fluids viz., water and 30\%propylene glycol and 70\% water mixture are used to study the effect of the 
heat transfer fluid on the performance of mantle heat exchanger. All these experiments are performed at two inlet temperatures of mantle fluid i.e., $50^{\circ} \mathrm{C}$ and $70^{\circ} \mathrm{C}$ respectively.

Table 2. Description of experiments conducted in Laboratory

\begin{tabular}{|l|c|l|l|c|}
\hline Experiment & $\begin{array}{l}\text { Mantle } \\
\text { inlet } \\
\text { position }\end{array}$ & $\begin{array}{l}\text { Mantle flow } \\
\text { rate(Kg/sec) }\end{array}$ & Mantle fluid & $\begin{array}{l}\text { Mantle } \\
\text { fluid inlet } \\
\text { temp }{ }^{\circ} \mathrm{C}\end{array}$ \\
\hline $\mathrm{F}_{\mathrm{i}}-\mathrm{M}_{0.5}-\mathrm{T}_{50}$ & $\mathrm{Fi}$ & 0.00833 & Water & 50 \\
\hline $\mathrm{F}_{\mathrm{i}}-\mathrm{M}_{0.5}-\mathrm{T}_{70}$ & $\mathrm{Fi}$ & 0.00833 & Water & 70 \\
\hline $\mathrm{S}_{\mathrm{i}}-\mathrm{M}_{0.5}-\mathrm{T}_{50}$ & $\mathrm{Si}$ & 0.00833 & Water & 50 \\
\hline $\mathrm{S}_{\mathrm{i}}-\mathrm{M}_{0.5}-\mathrm{T}_{70}$ & $\mathrm{Si}$ & 0.00833 & Water & 70 \\
\hline $\mathrm{F}_{\mathrm{i}}-\mathrm{M}_{0.75}-\mathrm{T}_{50}$ & $\mathrm{Fi}$ & 0.0125 & Water & 50 \\
\hline $\mathrm{F}_{\mathrm{i}}-\mathrm{M}_{0.75}-\mathrm{T}_{70}$ & $\mathrm{Fi}$ & 0.0125 & Water & 70 \\
\hline $\mathrm{F}_{\mathrm{i}}-\mathrm{M}_{0.5}-\mathrm{T}_{50}-\mathrm{G}$ & $\mathrm{Fi}$ & 0.00833 & Glycol/Water Mix. & 50 \\
\hline $\mathrm{F}_{\mathrm{i}}-\mathrm{M}_{0.5}-\mathrm{T}_{70}-\mathrm{G}$ & $\mathrm{Fi}$ & 0.00833 & Glycol/Water Mix. & 70 \\
\hline
\end{tabular}

Note: The abbreviations EXP and CFD used in these experiments represent experiment and simulation respectively.

The details of the experiments that are performed in the laboratory are given in the Table 2. All the experiments are specified with a specific notation as shown in the table 2 . The first digit in the specification ' $\mathrm{F}_{\mathrm{i}}$ ' or ' $\mathrm{S}_{\mathrm{i}}$ ' represents the first inlet or the second inlet, the second digit ' $\mathrm{M}_{0.5}$ ' or ' $\mathrm{M}_{0.75}$ ' represents mass flow rate of mantle fluid ( $0.5 \mathrm{lit} / \mathrm{min}$ or $\left.0.75 \mathrm{lit} / \mathrm{min}\right)$. The letter ' $\mathrm{T}_{50}$ ' or ' $\mathrm{T}_{70}$ ' gives the mantle fluid inlet temperature i.e., $50^{\circ} \mathrm{C}$ or $70^{\circ} \mathrm{C}$. The letter ' $\mathrm{G}$ ' stands for $30 \% \mathrm{glycol} / \mathrm{water}$ mixture.

\subsection{Measurement of experimental parameters}

In the heat storage test facility it is possible to control the flow rate in the mantle and mantle inlet temperature. During the experiments the following parameters are measured.

a) The mantle flow rate

b) The mantle inlet temperature

c) The mantle outlet temperature

d) The temperature of the domestic water in the inner tank at eight points inside the tank

e) The temperature at four points on the outside of the mantle wall

f) The ambient temperature.

3.4. Specifications of measuring devices: The specifications of the equipment used I these experiments are as follows. Tank with mantle heat exchanger: Stainless Steel of grade SS 304.

Thermocouples: copper -constantan with the specifications of P-200 ${ }^{\circ} \mathrm{C}(\mathrm{PT} 100)$

Digital temperature indicator panel: 216Y0811DTI

Measuring jar: $1000 \mathrm{ml}$ made up of glass to measure mantel flow rate.

\section{CFD Modeling}

The CFD code used in this work uses CFX-5 11.0 (Ansys, 2003) and is based on a finite volume method which uses an unstructured mesh containing tetrahedral and prism elements. This has the advantage that local numerical diffusion is reduced and is therefore suitable for complex flows with e.g. flow reversal. To reduce the number of iterations required for convergence, a false-time stepping method is imposed which guides the approximate solutions in a physically based manner to a steady-state solution. Buoyancy is modeled using the Boissinesq approximation in which the forces are modeled as source terms in the momentum equations (Cruickshank and Harrison, 2006).

Various models exist in CFX-5 code for modeling turbulent flow. Two-equation models based on the eddy-viscosity concept include the $\kappa-\varepsilon$ (Launder and Spalding, 1974), $\kappa-\omega$ (Wilcox, 1998) and Shear Stress Transport (SST) $\kappa-\omega$ based models (Menter, 1994). Compared to the commonly used $\kappa-\varepsilon$ turbulence model, the $\kappa-\omega$ model implies a new formulation for the near wall treatment which provides an automatic switch from a wall-function to a low-Reynolds number formulation based on the near-wall grid spacing. This makes it more accurate and more robust. The turbulence viscosity is assumed to be linked to the turbulence kinetic energy ( $\kappa$-equation) and turbulent frequency ( $\omega$-equation) instead of the turbulence dissipation rate ( $\varepsilon$-equation in the $\kappa-\varepsilon$ model). To overcome the sensitivity of the k- $\omega$ model to free stream conditions, the SST model is developed. It blends the k- $\omega$

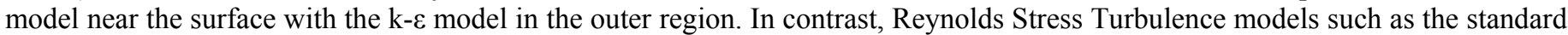
Launder-Reece-Rodi Isotropic Production (LRR-IP) model (Launder et al., 1975) and Second Moment Closure- $\omega$ (SMC- $\omega$ ) model (Wilcox, 1998), do not use the eddy-viscosity hypothesis, but solve transport equations for all components of the Reynolds 
stresses. This makes Reynolds Stress models more suited to complex flows. However, practice shows that they are often not superior to two-equation models because convergence difficulties often occur. The LRR-IP model is based on the k- $\varepsilon$ model, whereas the SMC- $\omega$ is based on the $\mathrm{k}-\omega$ model with the advantages already explained.

The influence of mesh resolution on temperatures and velocities in the wall boundary layer and on heat transfer at the heated plate are investigated by varying three key parameters for prism layer sizing: first prism size (use of $0.1 \mathrm{~mm}, 0.2 \mathrm{~mm}, 0.4 \mathrm{~mm}$, $1.0 \mathrm{~mm}$ and $2.0 \mathrm{~mm}$ ), core prism size (use of $1.33 \mathrm{~mm}, 2 \mathrm{~mm}, 3 \mathrm{~mm}$ and $4 \mathrm{~mm}$ ) and prism inflation (use of 1.5, 2.0 and 2.5). For investigations of constant core prism scales (by setting the prism inflation factor to unity) and prism inflation, a first prism size of $0.1 \mathrm{~mm}$ is used (refer Figure 5). In the sensitivity study of first prism sizes, a constant core prism scale of $2.0 \mathrm{~mm}$ is chosen. The first prism size determines the prism edge length in conversed direction of the surface normal for the first prism layer adjacent to the wall. The core prism size determines the prism edge length for the other prism elements towards the edge of the wall boundary layer and the outer region. A high mesh quality with finite element scales similar to the neighbouring elements reduces the risk of convergence problems. Therefore, with prism inflation, the prism layer size can be increased gradually towards the core such that the last prism layer size has a similar scale to the edges of the neighbouring tetrahedral elements.

The experiments are first simulated by taking into account the steady state natural convective flow on the tank side. A 3-D CFD model of a mantle heat exchanger coupled with a storage tank is developed with the same dimensions as the prototype unit. The CFD modeling of this type of heat exchanger would lead to very time consuming CFD simulations. In order to make the computational solution viable, the computational domain is simplified by modeling the mantle tank system into three regions which makes the problem simpler. Although, the model appears symmetric, grid restrictions require a full three dimensional analysis of the model. The purpose of the configuration is to investigate the influence of the flow on the stratification in the tank, the heat transfer inside the tank and the natural convection in the tank loop. The buoyancy for an incompressible fluid with constant properties except density and viscosity is modeled by using the Boussinesq approximation in ANSYS CFX 11.0. No slip and adiabatic boundary conditions are applied to the walls of the tank. The Boussinesq approximation uses the thermal expansion coefficient ( $\beta$ ) to capture natural convection. Thus, if $\beta$ is presumed to be constant, a linear dependency of the density of water on temperature is used.

The computational domain is simplified by modeling the top and bottom of the tank as flat walls, and the mantle-tank volume as the same as that of the prototype unit. High concentration mesh is used in the high temperature gradient regions near the heat transfer wall between the mantle and the storage tank. A total of 537077 grid points are used in the computational domain within the mantle gap and the inner tank. The number of grid points is given in Table 3.

For each simulation, the inlet temperature, flow rate of mantle fluid and flow rate of cold fluid from the experiments are specified as inputs to the CFD model. The typical running time for simulation is approximately 3 days. On the tank side, the temperature profile along the tank height is initialized based on the measured data. Heat loss from the tank is modeled using a constant convective heat transfer coefficient on the outer surfaces of the tank. All physical properties of water and glycol/water mixture are assumed to be constant except the density and viscosity in the buoyancy term in order to obtain faster numerical convergence. In order to have sufficient number of grid points for solving the flow and heat transfer in mantle (steady state model) particularly near the inlet jet impingement region and the high temperature gradient near the heat transfer wall, a mesh sensitivity check is undertaken by comparing the numerical results for different mesh sizes. Figures 4 and 5 show the geometry and mesh models of the work respectively.

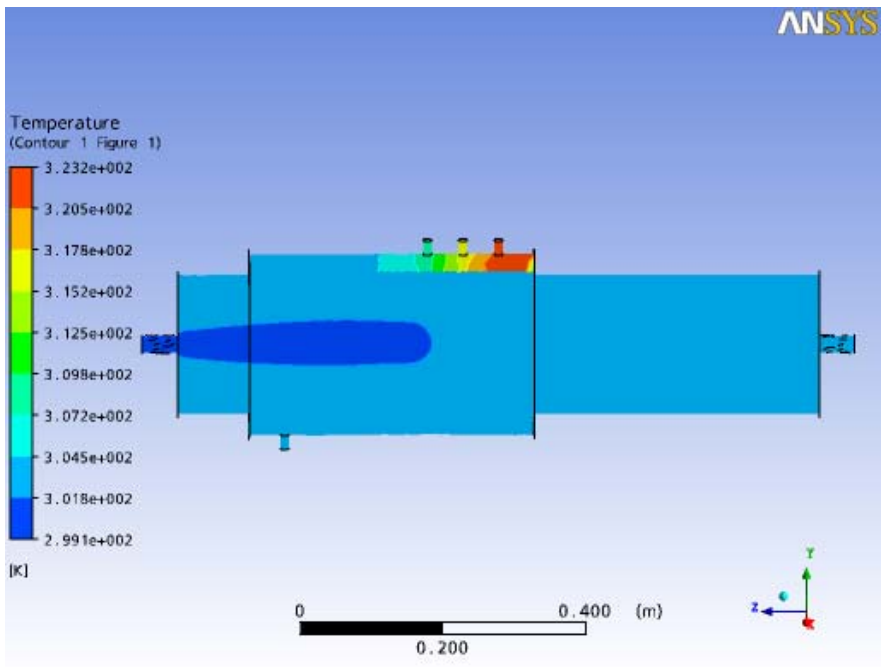

Figure 4: 3-D modeling of solar water tank with mantle heat exchanger

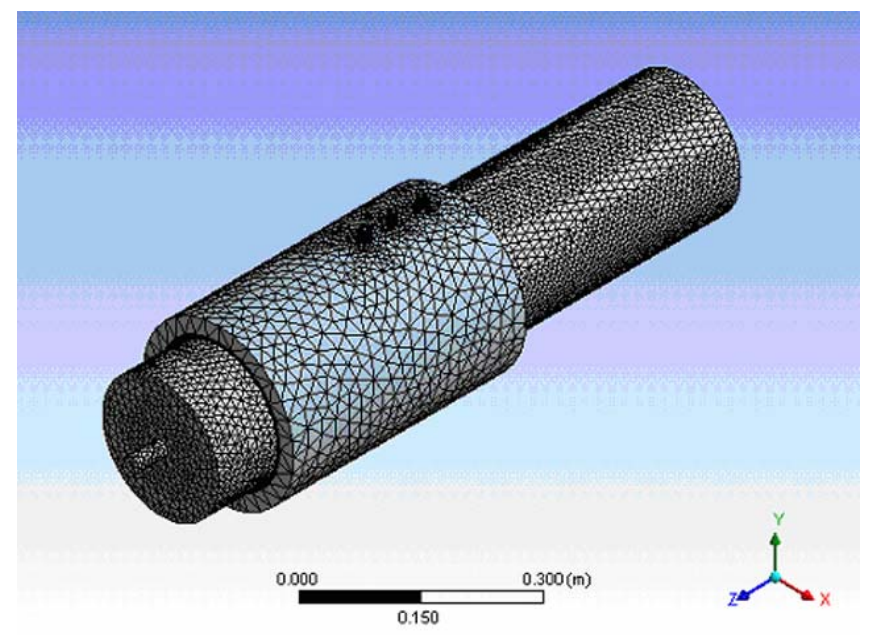

Fig. 5:3-D mesh model of solar water tank with mantle heat exchanger

Figure 5: 3-D mesh model of solar water tank with mantle heat exchanger. 
Table 3. Mesh information

\begin{tabular}{|c|c|c|}
\hline Domain & Nodes & Elements \\
\hline Region1 & 47456 & 256660 \\
\hline Region2 & 486540 & 1352471 \\
\hline Region3 & 3081 & 11108 \\
\hline
\end{tabular}

\subsection{Validation of models}

In order to examine the validity of the CFD simulation models used for heat transfer studies in mantle heat exchangers, simulated results are compared to experimental data. Figures $6 \& 7$ show a comparison of tank temperature stratification between experiments and simulations of the cold start test with inlet temperatures of $50^{\circ} \mathrm{C} \& 70^{\circ} \mathrm{C}$ with a flow rate of 0.5 lit $/ \mathrm{min}(0.00833$ $\mathrm{kg} / \mathrm{sec}$ ). As observed, the predicted tank temperature stratification is in reasonable agreement with the measured temperature profiles.

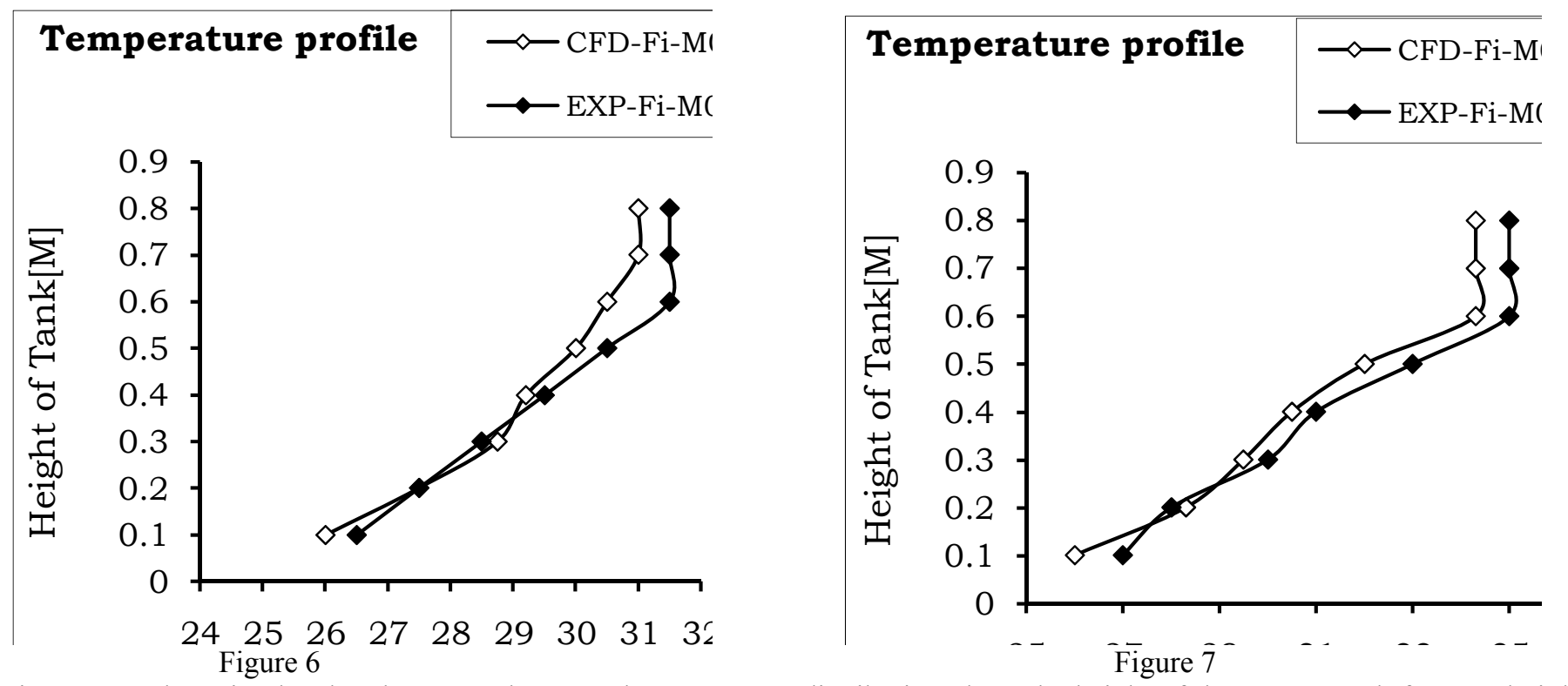

Figures 6 and 7: Simulated and measured core tank temperature distribution along the height of the storage tank for mantle inlet temperatures of $50^{\circ} \mathrm{C}$ and $70^{\circ} \mathrm{C}$ and at the flow rate of $0.5 \mathrm{lit} / \mathrm{min}$ at top inlet.

\section{Heat transfer coefficients}

Heat Transfer between the hot fluid in the mantle heat exchanger and cold fluid in the storage tank is governed by convective heat transfer on the hot side of the heat exchanger, conduction through the tank wall and natural convection circulation inside the tank (Baur et al., 1993).

The mean convective heat transfer coefficients (h) for the two convection processes in the mantle heat exchanger are determined using equations 1 and 2 based on the measured mantle side wall temperatures and the core temperatures (Soo Too et al., 2004).

Heat transfer coefficient on the mantle side,

$$
h m=\frac{Q}{A\left(T_{m}-T_{w, m}\right)}
$$

Heat transfer coefficient on the tank side,

$$
h t=\frac{Q}{A\left(T_{w, j}-T_{t}\right)}
$$

where $A$ is the available heat transfer area of the mantle heat exchanger $\left(\mathrm{m}^{2}\right)$,

$\mathrm{T}_{\mathrm{w}, \mathrm{t}}$ is the measured inner wall temperature on the tank side $\left({ }^{\circ} \mathrm{C}\right)$,

$T_{w, m}=\frac{Q t_{w}}{k_{w} A}+T_{w, t}$ is the wall temperature on the mantle side of the wall $\left({ }^{\circ} \mathrm{C}\right)$,

$\mathrm{t}_{\mathrm{w}}, \mathrm{k}_{\mathrm{w}}$ are the thickness(m) and thermal conductivity(W/mk) of the tank wall (Mercer et al., 1967; Morrison et al., 1999). 


\section{Results and discussions}

Investigating the process of heat transfer inside the storage tank for various governing parameters is the main objective of the present study. In this paper, the effect of following three parameters on heat transfer in energy storage systems are considered in order to study and quantify the thermal stratification in energy storage tanks.

1. Location of inlet position of mantle heat exchanger.

2. Mass flow rate of mantle fluid.

3. Type of heat transfer fluid.

\subsection{Effect of Location of Mantle Inlet Position on Heat Transfer Coefficients}
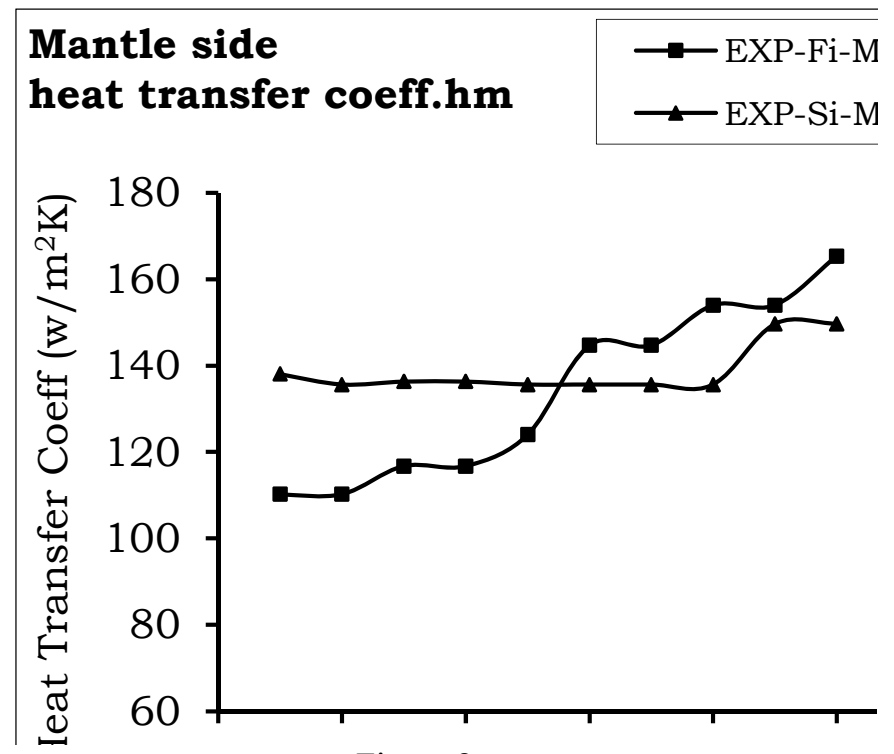

Figure 8
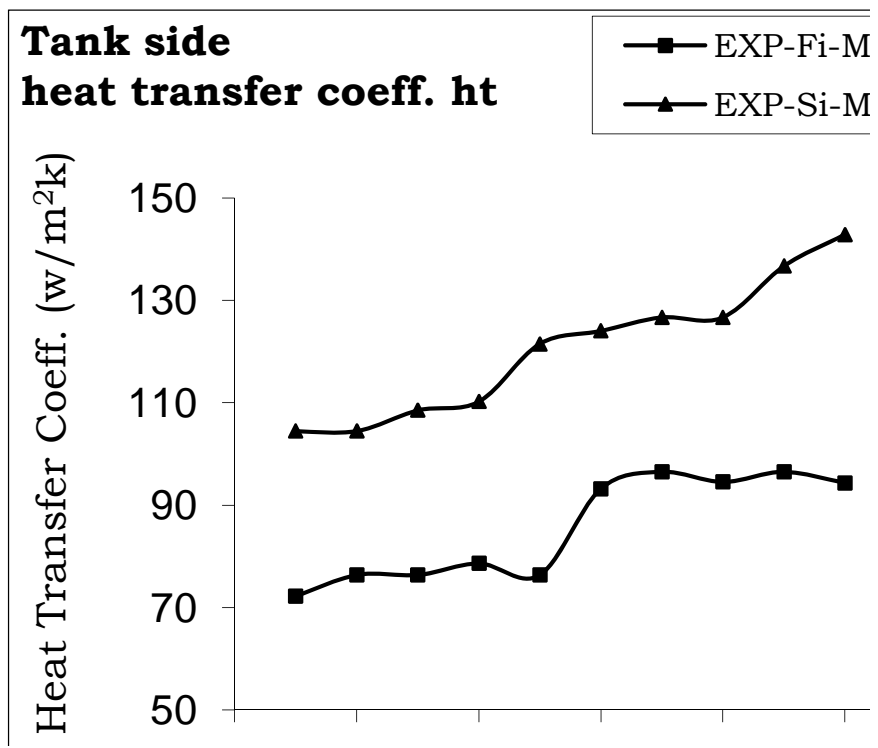

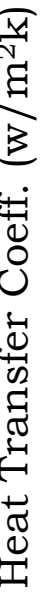

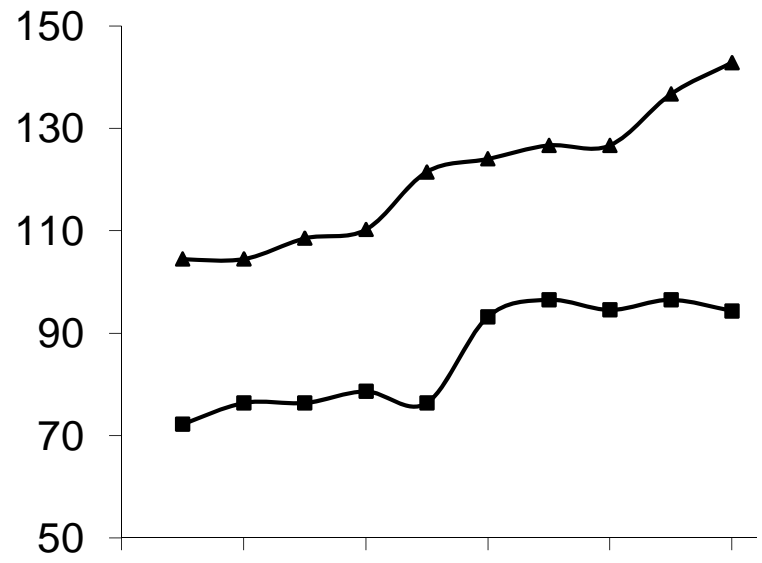

Figure 9

Figures $8 \&$ 9: Mantle and Tank side heat transfer coefficients, $h_{m} \& h_{t}$ for $50^{\circ} \mathrm{C}$ mantle fluid inlet temperature at both top and lower inlets.

By observing the mantle side heat transfer coefficient $\left(h_{m}\right)$ graph (Figure 8), it can be noticed that, $h_{m}$ value is less in the beginning for the top inlet and increases continuously, where as $h_{m}$ value (Figure 8) is almost constant for the second inlet. From the tank side heat transfer coefficient ht graph (Figure 9), it is observed that, $h_{t}$ values are greater for the second inlet flow than the first (top) inlet as there is a more heat transfer at the bottom of the mantle tank. It can be observed that, higher mantle fluid inlet temperature transfers more heat to the tank contents.

\subsection{Effect of mantle flow rate on heat transfer coefficients}

Figures 10 and 11 show the heat transfer coefficients on the mantle side and tank side of the heat exchanger for cold start test with mantle flow rates of 0.5 and $0.75 \mathrm{lit} / \mathrm{min}$ for inlet fluid temperatures of $50^{\circ} \mathrm{C}$. The mantle side heat transfer coefficient ' $\mathrm{h}_{\mathrm{m}}$ ' is found to be $165.4 \mathrm{w} / \mathrm{m}^{2} \mathrm{k}$ (Figure 10) while the tank side heat transfer coefficient 'ht' varies from $72.17 \mathrm{w} / \mathrm{m}^{2} \mathrm{k}$ to $96.47 \mathrm{w} / \mathrm{m}^{2} \mathrm{k}$ due to change of viscosity with temperature. The results obtained from cold start test with a mantle flow rate of $0.5 \mathrm{lit} / \mathrm{min}$ show that heat transfer coefficient on the mantle side $\mathrm{h}_{\mathrm{m}}$ is a factor which is 1.5 times higher than that on the tank side. When the mantle flow rate is increased to $0.75 \mathrm{lit} / \mathrm{min}$, the $\mathrm{h}_{\mathrm{m}}$ increases due to the impingement effect near the inlet and better flow distribution across the mantle at high flow rate. Even though higher mantle side heat transfer coefficients remain unchanged (Figure 10) the limiting factor on the performance of the mantle heat exchanger is primarily the natural convection in the storage tank.

As the inlet flow rate is increased, the mixing due to impingement could extend over the mantle, hence increasing the heat transfer coefficients. 


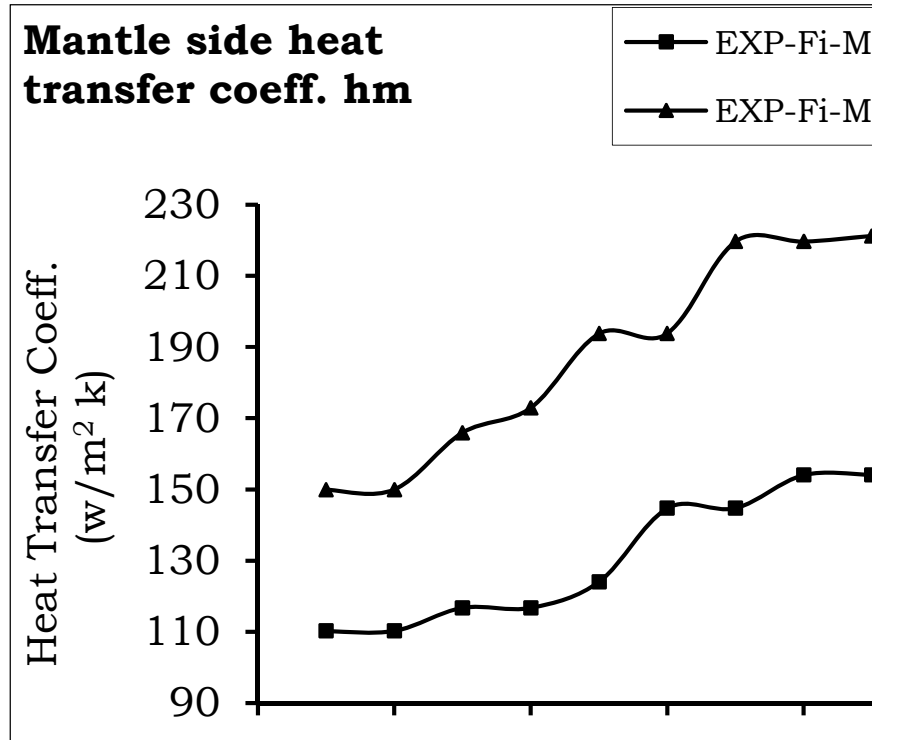

Figure 10
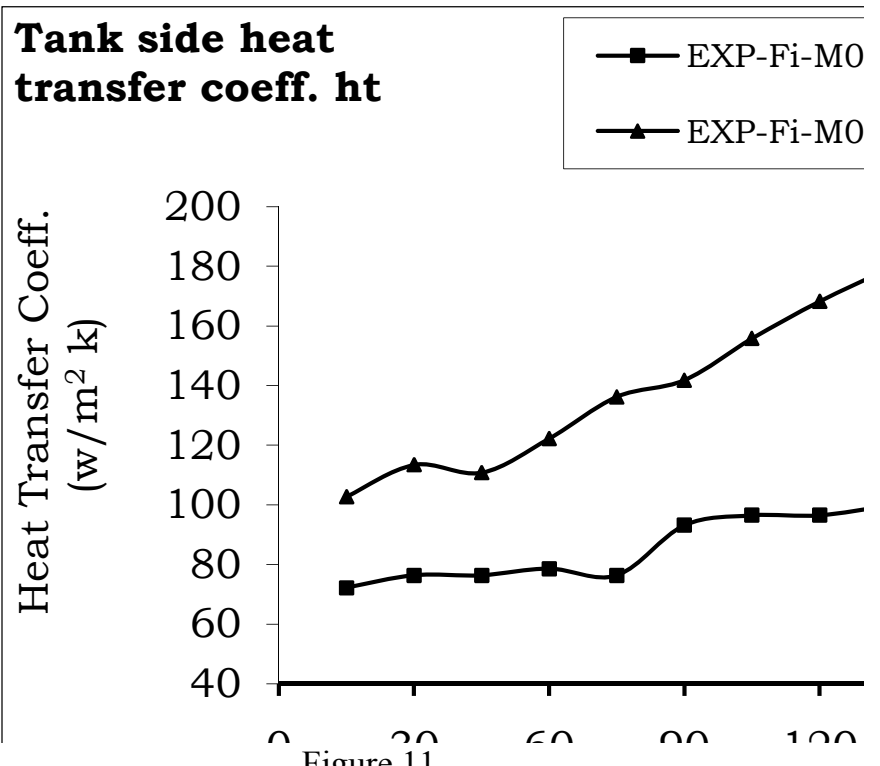

Figure 11

Figures $10 \&$ 11:Mantle and Tank side heat transfer coefficient, $\mathrm{h}_{\mathrm{m}} \& \mathrm{~h}_{\mathrm{t}}$ for $50^{\circ} \mathrm{C}$ mantle inlet temperature for 0.5 lit/min and 0.75 lit/min at top inlet.

\subsection{Effect of type of heat transfer fluid heat transfer coefficients}

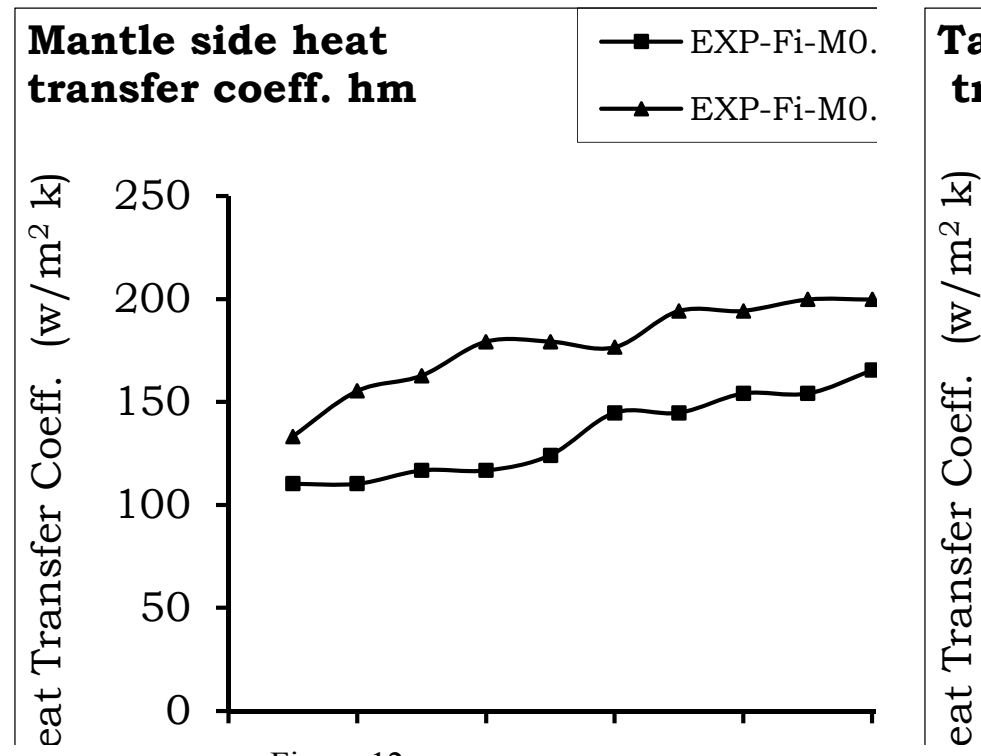

Figure 12
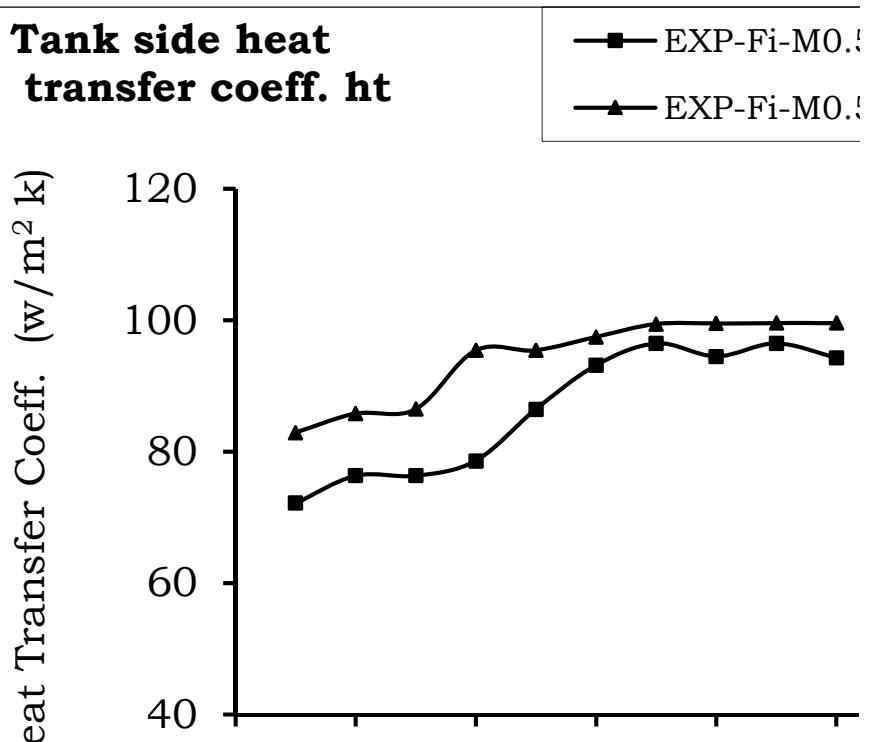

Figure 13

Figures 12 and 13: Mantle and Tank side heat transfer coefficient, $h_{m} \& h_{t}$ for $50^{\circ} \mathrm{c}$ mantle inlet temperature for water and glycolwater mixture.

In practice, a $30 \%$ propylene glycol-water mixture with high Prandtl number $\left(21.77\right.$ at $\left.45^{\circ} \mathrm{c}\right)$ and viscosity is typically used in the heat exchanger in order to provide freeze protection for solar water heaters. By utilising propylene glycol-water mixture as the mantle fluid, the lower range of Reynold's numbers can be extended. From the Figures 12 and 13, it can be seen that, the higher viscosity of glycol mixture decreases the Reynolds's number when compared to water. Higher specific heat and thermal conductivity of glycol-water mixture results in higher values of mantle side and tank side heat transfer coefficients. The viscosity of glycol is more in the beginning of the experiment which means that the flow will tend to become laminar and heat transfer is less. As the experiment is continued, the viscosity of glycol is reduced by absorbing heat and then the flow becomes turbulent and thus heat transfer is increased. It is observed that the heat transfer rate is more for the glycol-water mixture irrespective of mantle fluid inlet temperature. 


\section{Conclusions}

The heat transfer characteristics of a mantle heat exchanger with a single pass flow arrangement are investigated under controlled indoor conditions. Measurements showed that the tank is well mixed above the mantle level of the heat exchanger. The influence of mantle inlet location, the mantle fluid flow rate and the type of mantle fluid on the flow and heat transfer coefficients in a mantle is investigated using experimental and CFD simulated temperatures.

It can be noticed that, mantle side heat transfer coefficient $\left(\mathrm{h}_{\mathrm{m}}\right)$ value is low $\left(110 \mathrm{w} / \mathrm{m}^{2} \mathrm{~K}\right)$ for the first 30 minutes from the beginning of the experiment for the top inlet (50 mm below the top of the mantle) and is found to be increasing continuously up to $160 \mathrm{w} / \mathrm{m}^{2} \mathrm{~K}$ between 30 minutes and 150 minutes, where as, the $\mathrm{h}_{\mathrm{m}}$ value is observed to be almost constant $140 \mathrm{w} / \mathrm{m}^{2} \mathrm{~K}$ for the second inlet i.e., $100 \mathrm{~mm}$ below the top of the mantle tank throughout the test duration. In both the cases it is observed that heat exchange is taking place effectively from $0.1 \mathrm{~m}$ to $0.5 \mathrm{~m}$ height only. The heat transfer coefficients on either side of mantle heat exchanger are noticed to be higher for $70^{\circ} \mathrm{C}$ mantle fluid inlet temperature. The difference in heat transfer coefficients for $70^{\circ} \mathrm{C}$ and $50^{\circ} \mathrm{C}$ inlet temperatures is found to be marginal on mantle side whereas it is considerable on tank side. The tank side heat transfer coefficient, $h_{t}$ values are greater for the second inlet than the first (top) inlet as there is a more heat transfer at the bottom of the mantle tank. It can also be observed that, at higher mantle fluid inlet temperature $\left(70^{\circ} \mathrm{C}\right)$, more heat is transferred to the tank contents.

The increased mass flow rate from $0.5 \mathrm{lit} / \mathrm{min}$ to $0.75 \mathrm{lit} / \mathrm{min}$ is resulting in increased mantle side heat transfer coefficients. The experimental results showed that $h_{m}$ value is $190 \mathrm{w} / \mathrm{m}^{2} \mathrm{~K}$ for $0.75 \mathrm{lit} / \mathrm{min}$ flow rate and $120 \mathrm{w} / \mathrm{m}^{2} \mathrm{~K}$ for $0.5 \mathrm{lit} / \mathrm{min} 90$ minutes after the beginning of the experiment. This can be for the reason that the inlet jet impingement on the back wall adjacent to the inlet induces a region of localized turbulent flow.

With propylene glycol-water mixture as the mantle fluid, the Reynold's number is found to be low due to the higher viscosity of glycol mixture when compared to water. However higher specific heat and thermal conductivity of glycol-water mixture results in higher values of mantle side and tank side heat transfer coefficients $200 \mathrm{w} / \mathrm{m}^{2} \mathrm{~K}$ and $130 \mathrm{w} / \mathrm{m}^{2} \mathrm{~K}$ respectively. The disadvantage with the glycol-water mixture is that, glycol should be removed as hazardous waste at regular intervals.

The second inlet position (100 mm below the top of the mantle tank) for the mantle heat exchanger at high inlet temperature of $70^{\circ} \mathrm{C}$, high mass flow rates of mantle fluid and the mantle fluid with high thermal properties can improve the performance of the mantle heat exchangers. It is also observed that both experimental and simulated temperatures are in good agreement with each other.

\section{Nomenclature}

SDHWS Solar domestic hot water system

$\mathrm{T}_{\mathrm{i}} \quad$ heat exchanger inlet temperature $\left({ }^{0} \mathrm{~K}\right)$

$\mathrm{T}_{\mathrm{o}} \quad$ Heat exchanger outlet temperature $\left({ }^{0} \mathrm{~K}\right)$

$\mathrm{T}_{\mathrm{w}} \quad$ Tank wall temperature $\left({ }^{0} \mathrm{~K}\right)$

$\mathrm{T}_{\mathrm{t}} \quad$ Temperature of fluid in tank $\left({ }^{0} \mathrm{~K}\right)$

A Available heat exchange area $\left(\mathrm{m}^{2}\right)$

$\mathrm{h}_{\mathrm{m}} \quad$ Mantle side convective heat transfer coefficient $\left(\mathrm{w} / \mathrm{m}^{2} \mathrm{~K}\right)$

$\mathrm{h}_{\mathrm{t}} \quad$ Tank side convective heat transfer coefficient $\left(\mathrm{w} / \mathrm{m}^{2} \mathrm{~K}\right)$

$\mathrm{m} \quad$ Mantle fluid mass flow rate $(\mathrm{kg} / \mathrm{sec})$

Q Heat supplied to the system (W)

$\Delta \mathrm{T}_{\mathrm{lm}} \quad$ log-mean temperature difference $\left({ }^{0} \mathrm{~K}\right)$

$\mathrm{T} \quad$ Time $(\mathrm{sec})$

$\mathrm{t}_{\mathrm{w}} \quad$ tank material wall thickness (m)

$\mathrm{k}_{\mathrm{w}} \quad$ thermal conductivity of tank material(w/m.k)

\section{References}

Ansys CFX, 2003: CFX-5 Solver Models and Theory User Manuals, Version 5.6.

Baur, J.M., Klein, S., Beckman, W.A., 1993. Simulation of water tanks with mantle heat exchangers. Proceedings, ASES Solar Vol. 93, pp. 286- 291.

Cruickshank, C.A. and Harrison, S.J. 2006. Simulation and testing of stratified multi-tank, thermal storages for solar heating systems. Proceedings of the Euro Sun 2006 Conference, Glasgow, Scotland.

Furbo, S., Knudsen, S., 2005. Heat transfer correlations in mantle-tanks, ISES Solar World Congress, Orlando, USA.

Knudsen, S., Furbo, S., 2004. Thermal stratification in vertical mantle heat exchangers with application to solar domestic hot water systems. Applied Energy, Vol.78, pp. 257-272.

Launder B.E., Spalding D.B., 1974. The numerical computation of turbulent flows, Comp. Meth. in Applied Mech. Eng., Vol 3, pp 269-289. 
Launder B., Reece G. and Rodi W., 1975. Progress in the development of a Reynolds-stress turbulence closure, J. Fluid Mech., Vol. 68, No. 3, pp 537-566.

Mercer, W.E., Pearce, W.M., Hitchcock, J.E., 1967. Laminar forced convection in the entrance region between parallel flat plates. ASME Journal of Heat Transfer, Vol. 89, 251-257.

Menter, F.R., 1994. Two-equation eddy viscosity turbulence models for engineering applications, AIAA Journal, Vol. 32, No. 8, pp. 1598-1605.

Morrison, G.L., Rosengarten, G., Behnia, M., 1999. Mantle heat exchangers for horizontal tank thermosyphon solar water heaters, Solar Energy, 67, 53-64.

Shah, L.J., Furbo, S., 1998. Correlation of experimental and theoretical heat transfer in mantle-tanks used in low flow SDWH systems. Solar Energy, Vol. 64, 245-256.

Shah, L.J., 2000. Heat transfer correlation for vertical mantle heat exchangers. Solar Energy, Vol. 69, 157-171.

Shah, L.J., Morrison, G.L., Behnia, M., 1999. Characteristics of vertical mantle heat exchangers for solar water heaters. Solar Energy, Vol. 67, pp. 79-91.

Soo Too Y.C., Morrison GL and Behnia M, 2004. Vertical mantle heat exchangers for solar water heaters, Proceedings of ANZSES Annual Conference, December, Perth, Australia.

Wilcox D.C., 1998: Turbulence modeling for CFD, 2nd edn., DCW Industries Inc., Canada.

\section{Biographical notes}

G. Naga Malleshwara Rao is an Associate Professor in the Department of Mechanical Engineering at Intel Engineering College, Ananthapur of Andhra Pradesh State, India. His current area of research includes Heat transfer and Renewable energy. He has presented many articles in national and international conferences. He also worked as Training and Placement Officer at Intel Engineering College between 2006 and 2009. He is a life member of IE (India). He is having a total experience of 17 years of which 6 years is Industrial and 11 years academic.

Dr K. Hema Chandra Reddy received MTech and PhD. from Jawaharlal Nehru Technological University (JNTU), Hyderabad, India. He is a Professor in the Department of Mechanical Engineering, JNTU College of Engineering Ananthapur. He also worked as Training and Placement Officer at JNTU College of Engineering Ananthapur and during this tenure many of their students are globally placed. Currently he is the Director of Academics and Planning at Jawaharlal Nehru Technological University, Ananthapur. He is a Fellow of IE (India), and life member of various professional bodies. Many research scholars are pursuing their $\mathrm{PhDs}$ under his esteemed guidance and some of them have been awarded.

M. Sreenivasa Reddy is working as a Technical Assistant at JNTU College of Engineering, Ananthapur. He received his MTech from JNTU, Hyderabad. He submitted his PhD in JNTU, Ananthapur and waiting for the final viva-voce. His area of research includes Internal Combustion Engines.

Received, March 2010

Accepted, April 2010

Final acceptance in revised form, April 2010 